Daniel De Backer

Gernot Marx

Andrew Tan

Christopher Junker

Marc Van Nuffelen

Lars Hüter

Willy Ching

Frédéric Michard

Jean-Louis Vincent

\section{Arterial pressure-based cardiac output monitoring: a multicenter validation of the third-generation software in septic patients}

Received: 14 July 2009

Accepted: 29 September 2010

Published online: 10 December 2010

(C) The Author(s) 2010. This article is published with open access at Springerlink.com

This article is discussed in the editorial available at: doi:10.1007/s00134-010-2109-9.

Electronic supplementary material

The online version of this article (doi:10.1007/s00134-010-2098-8) contains supplementary material, which is available to authorized users.

D. De Backer $(\bowtie) \cdot$ M. Van Nuffelen .

J.-L. Vincent

Department of Intensive Care,

Erasme University Hospital, Université

Libre de Bruxelles, Route de Lennik 808,

1070 Brussels, Belgium

e-mail: ddebacke@ulb.ac.be

Tel.: +32-2-5553380

Fax: $+32-2-5554698$

G. Marx

Department of Surgical Intensive Care,

Aachen University Hospital,

Pauwelsstrasse 52074, Aachen, Germany

A. Tan $\cdot$ W. Ching

Intensive Care Unit, Queen's Medical

Center, 1301 Punchbowl Street,

Honolulu, HI 96813, USA
C. Junker

Intensive Care Unit, George Washington

University Medical Center, 2300 Eye Street

NW, Washington DC 20037, USA

L. Hüter

Anesthesiology and Intensive Care, Jena University Hospital, Erlanger Allee, Jena 07747, Germany

F. Michard

Edwards LifeSciences, Critical Care

Europe, Route de l'Etraz 70,

1260 Nyon, Switzerland

Abstract Purpose: Second-generation FloTrac software has been shown to reliably measure cardiac output $(\mathrm{CO})$ in cardiac surgical patients. However, concerns have been raised regarding its accuracy in vasoplegic states. The aim of the present multicenter study was to investigate the accuracy of the thirdgeneration software in patients with sepsis, particularly when total systemic vascular resistance (TSVR) is low. Methods: Fifty-eight septic patients were included in this prospective observational study in four university-affiliated ICUs. Reference $\mathrm{CO}$ was measured by bolus pulmonary thermodilution (iCO) using 3-5 cold saline boluses. Simultaneously, $\mathrm{CO}$ was computed from the arterial pressure curve recorded on a computer using the second-generation $\left(\mathrm{CO}_{\mathrm{G} 2}\right)$ and third-generation $\left(\mathrm{CO}_{\mathrm{G} 3}\right)$ FloTrac software. $\mathrm{CO}$ was also measured by semi-continuous pulmonary thermodilution (CCO). Results: A total of 401 simultaneous measurements of $\mathrm{iCO}, \mathrm{CO}_{\mathrm{G} 2}, \mathrm{CO}_{\mathrm{G} 3}$, and $\mathrm{CCO}$ were recorded. The mean $(95 \% \mathrm{CI})$ biases between $\mathrm{CO}_{\mathrm{G} 2}$ and $\mathrm{iCO}, \mathrm{CO}_{\mathrm{G} 3}$ and $\mathrm{iCO}$, and $\mathrm{CCO}$ and $\mathrm{iCO}$ were $-10(-15$ to -5$) \%[-0.8(-1.1$ to $-0.4) \mathrm{L} / \mathrm{min}], 0$ ( -4 to 4$) \%$ [0 ( -0.3 to 0.3$) \mathrm{L} / \mathrm{min}]$, and $9(6-13) \%$ [0.7 (0.5-1.0) L/min], respectively. The percentage errors were 29 (20-37)\% for $\mathrm{CO}_{\mathrm{G} 2}, 30$ (24-37)\% for $\mathrm{CO}_{\mathrm{G} 3}$, and $28(22-34) \%$ for CCO. The difference between $\mathrm{iCO}$ and $\mathrm{CO}_{\mathrm{G} 2}$ was significantly correlated with TSVR $\left(r^{2}=0.37, p<0.0001\right)$. A very weak $\left(r^{2}=0.05\right)$ relationship was also observed for the difference between $\mathrm{iCO}$ and $\mathrm{CO}_{\mathrm{G} 3}$. Conclusions: In patients with sepsis, the third-generation FloTrac software is more accurate, as precise, and less influenced by TSVR than the secondgeneration software.

Keywords Cardiac output . Monitoring · Non-invasive . Systemic vascular resistance 


\section{Introduction}

The computation of stroke volume from an arterial pressure waveform is not a new concept. Proposed for the first time in 1904 [1], stroke volume calculation has been improved and refined by many investigators and companies over the last century. Deriving stroke volume from a peripheral arterial pressure curve is very challenging. Indeed, the arterial pressure waveform depends not only on stroke volume but also on arterial compliance, vascular tone, and reflection waves [2,3]. Most methods currently available on the market require regular manual calibration to capture differences in arterial compliance and vascular tone from one patient to another and in a given patient from one time to another [2,3]. Therefore, the accuracy of these techniques is highly dependent on the delay between two manual calibrations and on the hemodynamic stability of the patient [4].

A self-calibrated method has been available on the market since 2005 (FloTrac, Edwards LifeSciences, Irvine, CA). This method was described in detail elsewhere [5]. Briefly, cardiac output (CO) is computed from the equation:

$$
\mathrm{CO}=\text { pulse rate } \times \text { APsd } \times K,
$$

where APsd is the standard deviation of arterial pressure and $K$ an autocalibration factor derived from a proprietary multivariate equation. $\mathrm{CO}$ is updated every $20 \mathrm{~s}$. This equation includes biometric variables (e.g., age and sex, which, according to the work of Langewouters et al. [6, 7], are known to affect arterial compliance) and "shape variables" describing in mathematical or statistical terms the shape of the arterial pressure curve. The equation was developed from and validated in a human database of arterial pressure tracings and thermodilution $\mathrm{CO}$ reference values.

The first-generation software was developed from a limited human database, and the multivariate equation updated only every $10 \mathrm{~min}$. Validation studies were somewhat disappointing [8,9]. The second-generation software is based on a larger human database, and the multivariate equation (i.e., $K$ ) is updated every minute (allowing the rapid capture of acute changes in vascular tone). The second-generation software has been shown to be reliable in the measurement of $\mathrm{CO}$, and in the tracking of acute changes in $\mathrm{CO}$ but these studies were conducted mostly in cardiac surgery patients [10-13]. Some concerns have been raised regarding the second-generation software in patients with hyperdynamic and vasoplegic states [14-17]. A relationship (logarithmic) has been established between FloTrac accuracy and systemic vascular resistance (SVR), with FloTrac underestimating CO when SVR is low $[15,16]$. To address this limitation, a third-generation software was recently developed from an even larger human database, which contains a greater proportion of hyperdynamic and vasoplegic patients.
The aim of the present multicenter study was to investigate, in a separate cohort of patients than that used to develop the algorithm, whether the third-generation software is able to accurately measure $\mathrm{CO}$ in patients with sepsis, particularly when SVR is low.

\section{Materials and methods}

The study was conducted in four university-affiliated intensive care units (ICUs) after approval by the ethical committee of each institution. Written informed consent was given by all patients or their legal guardian. Patients with sepsis [18], with a pulmonary artery catheter in place for hemodynamic monitoring, and with a peripheral arterial line in place for continuous blood pressure monitoring were considered for the study. Patients younger than 18 years old or less than $40 \mathrm{~kg}$ in weight (as this may limit the use of continuous $\mathrm{CO}$ measurement with a pulmonary artery catheter), with significant aortic or tricuspid valve regurgitation, or being treated with an intra-aortic balloon pump were excluded.

\section{Measurements}

All patients had a pulmonary artery catheter connected to a specific monitor (Vigilance, Edwards LifeSciences, Irvine, CA, USA) for CO measurement by bolus thermodilution (iCO) and by semi-continuous thermodilution (CCO). Bolus measurements were obtained by using 3-5 cold $\left(<10^{\circ} \mathrm{C}\right) 10 \mathrm{~mL}$ saline boluses (CO-Set, Edwards) randomly injected throughout the respiratory cycle. The temperature of the injectate was measured at the site of injection. The consistency of the thermodilution curve was judged visually on the monitor and all sets of iCO measurements with a reproducibility less than $15 \%$ were considered for analysis [19]. CCO was obtained with automated and intermittent heating of filament wire. Five $\mathrm{CCO}$ values were averaged over a 5 -min period $(2 \mathrm{CCO}$ values before and $3 \mathrm{CCO}$ values after iCO measurements). All patients also had a radial $(n=32)$ or femoral $(n=26)$ arterial catheter for continuous arterial pressure monitoring. Quality of damping was ensured by visualization of oscillation decay after flushing the lines. The arterial pressure curve was recorded on a computer via a highfidelity pressure transducer (FloTrac, Edwards Lifesciences) and $\mathrm{CO}$ was computed off-line from the arterial pressure curve using the second-generation $\left(\mathrm{CO}_{\mathrm{G} 2}\right.$, version 1.14) and the third-generation $\left(\mathrm{CO}_{\mathrm{G} 3}\right)$ FloTrac software. Investigators measuring and collecting $\mathrm{iCO}$ values were, therefore, blind to the FloTrac $\mathrm{CO}$ measurements. Fifteen $\mathrm{CO}_{\mathrm{G} 2}$ and $\mathrm{CO}_{\mathrm{G} 3}$ values were averaged over a 5 -min period ( 7 values before and 8 values after iCO measurements). 
Mean arterial pressure (MAP) was also recorded and total SVR (TSVR) was calculated [central venous pressure (CVP) was not collected] by using the equation:

$$
\mathrm{TSVR}=\mathrm{MAP} \times 80 / \mathrm{iCO}
$$

where iCO was the reference $\mathrm{CO}$ for the study.

Hemodynamic measurements were performed at the discretion of the attending physician, suggested to be at least every $4 \mathrm{~h}$ during daytime whereas more measurements could be obtained in case of hemodynamic instability or to evaluate the effects of therapeutic interventions. Patients were followed for $48 \mathrm{~h}$.

The study was sponsored by Edwards Lifesciences. Computation of $\mathrm{CO}$ from arterial traces was performed by Edwards Lifesciences' technicians. The investigators had full control of the database which was locked before analysis. Data analysis was performed by the investigators (DDB). The manuscript was drafted by the first author, and all authors reviewed the manuscript.

\section{Statistical analysis}

We used SPSS software (version 13). Results are expressed as mean $\pm \mathrm{SD}$. A $p<0.05$ was considered significant. Bias was calculated as the mean difference of $\mathrm{CO}_{\mathrm{G} 3}, \mathrm{CO}_{\mathrm{G} 2}$, or $\mathrm{CCO}$ minus iCO. Limits of agreement (LOA) were calculated as $\pm 2 \mathrm{SD}$ of these differences. Bias and LOA are presented as a percentage (absolute values are also provided in brackets) as suggested by Critchley and Critchley [20], because a difference between measurements (bias) of $1 \mathrm{~L} / \mathrm{min}$, for example, is more clinically significant at lower than at higher COs. The percentage error was calculated as two times the SD of the bias over the mean $\mathrm{iCO}$, as previously recommended $[16,20]$. A percentage error less than $30 \%$ was considered as satisfactory [20]. The precision of the reference technique (iCO) was calculated as twice its coefficient of variability of individual bolus injections at each iCO measurement [21]. Differences in bias were evaluated by a Student $t$ test with Bonferroni correction for multiple comparisons. Differences in LOA were evaluated with a Kolmogorov-Smirnov test [22]. The relationships between TSVR and the differences of $\mathrm{CO}_{\mathrm{G} 3}$, $\mathrm{CO}_{\mathrm{G} 2}$, or $\mathrm{CCO}$ minus iCO were tested for each method using a logarithmic regression analysis.

As multiple measurements were obtained, two different analyses were performed to limit the influence of multiple measurements per patient. First we used a correction for Bland and Altman analysis for multiple measurements [23, 24]. Second, as all analyses cannot be corrected by this technique, we also present (in the ESM) an analysis conducted using only the first measurement for each patient.

Finally, we evaluated the ability of the different techniques to track changes in $\mathrm{CO}$ using pairs of successive $\mathrm{CO}$ measurements, with each $\mathrm{CO}$ measurement used only once. For this purpose, the direction and the amplitude of changes were evaluated [21]. Receiver operating characteristic (ROC) curves were constructed to evaluate the ability of each technique to detect concordant directional changes in $\mathrm{CO}$ of at least $15 \%$, with iCO used as reference.

\section{Results}

A total of 58 patients admitted to four ICUs (Honolulu, Hawaii, USA $n=20$; Jena, Germany $n=15$; Brussels, Belgium $n=14$; and Washington DC, USA $n=9$ ) were enrolled in the study. Patient characteristics are summarized in Table 1. Hemodynamic profiles are provided in Table 1 (aggregate of all measurements during the study period) and in Table 1 in the ESM (baseline measurements). A total of $401(6.9 \pm 5.0$ per patient) simultaneous determinations of $\mathrm{iCO}, \mathrm{CO}_{\mathrm{G} 2}, \mathrm{CO}_{\mathrm{G} 3}$, and $\mathrm{CCO}$ were available for comparison. The median time between measurements was 238 (percentiles 25 and 75: 158 and $443 \mathrm{~min}$, respectively) min.

Table 1 Patient characteristics

\begin{tabular}{ll}
\hline Age (years) & $62 \pm 14$ \\
Sex (M/F) & $40 / 18$ \\
Weight $(\mathrm{kg})$ & $81 \pm 24$ \\
Height $(\mathrm{cm})$ & $169 \pm 12$ \\
Body surface area $\left(\mathrm{m}^{2}\right)$ & $1.88 \pm 0.25$ \\
Body mass index & $28 \pm 8$ \\
History of cardiac disease & $25(43 \%)$ \\
History of vascular disease & $4(7 \%)$ \\
Patient type & \\
Medical & $41(71 \%)$ \\
Surgical (post-op.) & $13(22 \%)$ \\
Trauma & $4(7 \%)$ \\
Vasoactive support & $39(67 \%)$ \\
Norepinephrine & $9(16 \%)$ \\
Vasopressin & $1(2 \%)$ \\
Dopamine & $16(28 \%)$ \\
Inotropic support & $7(12 \%)$ \\
Dobutamine & $5(9 \%)$ \\
Milrinone & $51(88 \%)$ \\
Levosimendan & \\
Mechanical ventilation & \\
Hemodynamic profile (aggregate measurements over the entire \\
study period) & $97 \pm 19$ \\
Heart rate (bpm) & $76 \pm 11$ \\
Mean arterial pressure (mmHg) & $7.5 \pm 2.0$ \\
iCO (L/min) & $6.5 \pm 1.5$ \\
CO G2 (L/min) & $7.3 \pm 2.1$ \\
CO $(\mathrm{L} / \mathrm{min})$ & $8.1 \pm 2.1$ \\
CCO (L/min) & $875 \pm 283$ \\
TSVR (dyn/(s cm 5 )) &
\end{tabular}

$T S V R$ total systemic vascular resistance; $i C O$ cardiac output measured by bolus thermodilution; $\mathrm{CO}_{G 2}$ cardiac output measured by second-generation FloTrac; $\mathrm{CO}_{G 3}$ cardiac output measured by third-generation FloTrac; $C C O$ cardiac output measured by semicontinuous thermodilution 
Accuracy and precision of $\mathrm{CO}$ measurements

Overall, iCO ranged from 2.7 to $14.6 \mathrm{~L} / \mathrm{min}, \mathrm{CO}_{\mathrm{G} 2}$ from 2.5 to $14.4 \mathrm{~L} / \mathrm{min}, \mathrm{CO}_{\mathrm{G} 3}$ from 2.5 to $17 \mathrm{~L} / \mathrm{min}$, and $\mathrm{CCO}$ from 2.8 to $16 \mathrm{~L} / \mathrm{min}$. The precision of $\mathrm{iCO}$ was $12.4 \%$. The mean bias and LOA were -10 and $29 \%(2.2 \mathrm{~L} / \mathrm{min})$ between $\mathrm{CO}_{\mathrm{G} 2}$ and $\mathrm{iCO}, 0$ and $30 \%(2.2 \mathrm{~L} / \mathrm{min})$ between $\mathrm{CO}_{\mathrm{G} 3}$ and $\mathrm{iCO}$, and 9 and $28 \%(2.1 \mathrm{~L} / \mathrm{min})$ between $\mathrm{CCO}$ and $\mathrm{iCO}$ (Fig. 1). The bias between $\mathrm{CO}_{\mathrm{G} 3}$ and iCO did not differ from $0(0.2 \%, 95 \% \mathrm{CI}-3.7$ to $4.2 \%, p=0.90)$ and
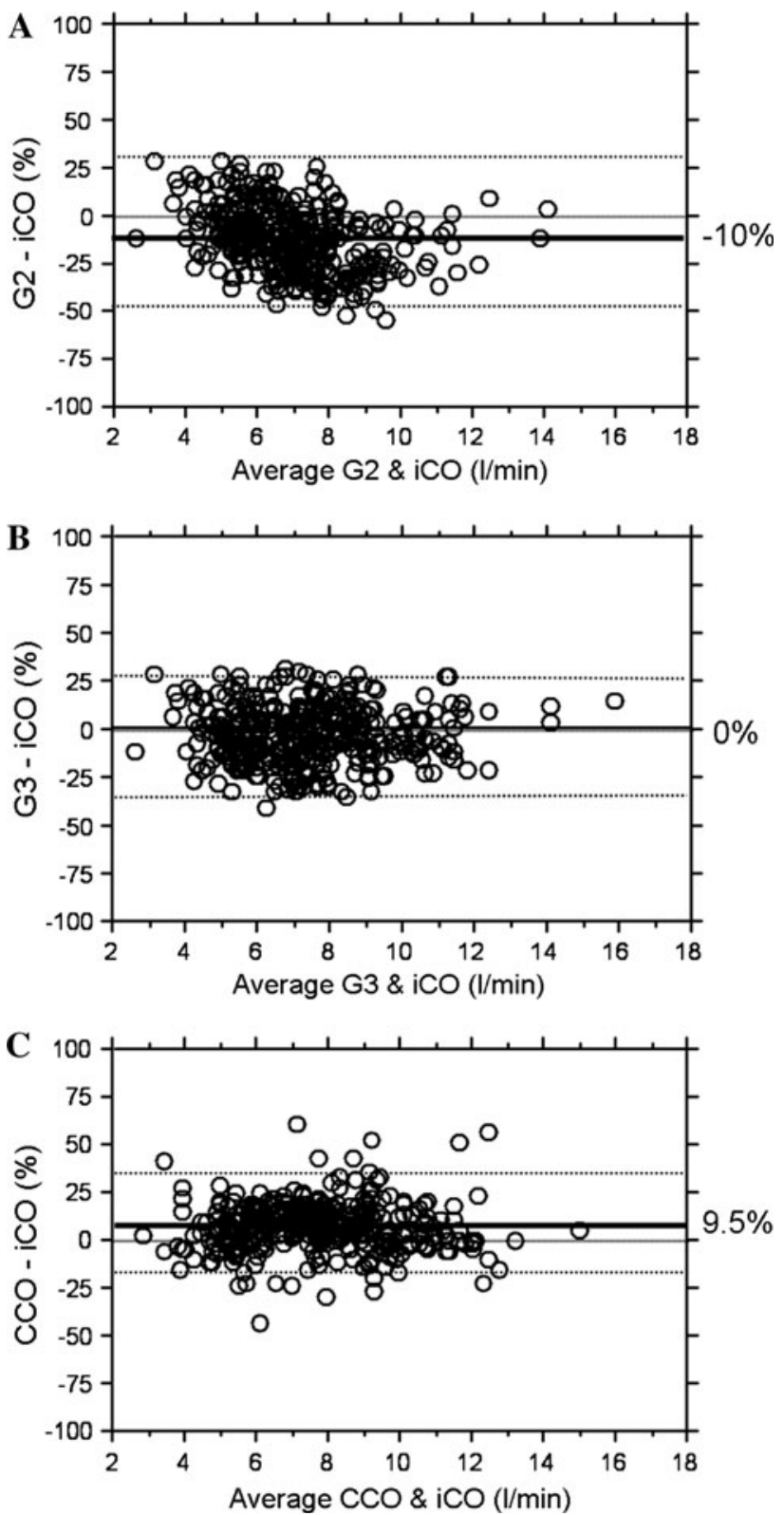

Fig. 1 Bland \& Altman representations of $\mathrm{CO}_{\mathrm{G} 2}, \mathrm{CO}_{\mathrm{G} 3}$, and $\mathrm{CCO}$ versus iCO. Panel a shows relation between $\mathrm{CO}_{\mathrm{G} 2}$ and iCO, panel b $\mathrm{CO}_{\mathrm{G} 3}$ and $\mathrm{iCO}$, and panel $\mathbf{c} \mathrm{CCO}$ and iCO. The bias and limits of agreements, computed with correction for multiple measurements $[23,24]$, are provided in Table 2 was significantly less negative than the bias between $\mathrm{CO}_{\mathrm{G} 2}$ and iCO $(p<0.0001)$. Kolmogorov-Smirnov testing showed significant differences in the LOA between $\mathrm{CO}_{\mathrm{G} 3}$ and $\mathrm{CO}_{\mathrm{G} 2}$ but not between $\mathrm{CO}_{\mathrm{G} 3}$ and $\mathrm{CCO}(p<0.001$ and 0.59 , respectively). LOA were similar when $\mathrm{CO}_{\mathrm{G} 3}$ was compared with $\mathrm{iCO}$ and $\mathrm{CCO}\left(27.2 \pm 6.2 \%\right.$ for $\mathrm{CO}_{\mathrm{G} 3}$, other data not shown). Similar results were observed when a correction for multiple measurements per patient was not applied (Table 2).

When only the first measurement of $\mathrm{CO}$ obtained at inclusion of the patient was considered, similar bias and LOA were observed (Table 2, and Fig. 1 in the ESM; hemodynamic data are presented in Table 1 in the ESM). The bias between $\mathrm{CO}_{\mathrm{G} 3}$ and iCO did not differ from $0(-0.2 \%, 95 \% \mathrm{CI}$ -4 to $+4, p=0.90)$ and was significantly less negative than the bias between $\mathrm{CO}_{\mathrm{G} 2}$ and $\mathrm{iCO}(p<0.0001)$. KolmogorovSmirnov testing showed significant differences in LOA between $\mathrm{CO}_{\mathrm{G} 3}$ and $\mathrm{CO}_{\mathrm{G} 2}$ and between $\mathrm{CO}_{\mathrm{G} 3}$ and $\mathrm{CCO}$ $(p<0.001$ and $<0.01$, respectively).

Influence of TSVR on the accuracy of CO measurements

The difference between $\mathrm{iCO}$ and $\mathrm{CO}_{\mathrm{G} 2}$ was significantly correlated with TSVR $\left(r^{2}=0.37, p<0.0001\right)$ (Fig. 2). A very weak $\left(r^{2}=0.05\right)$ but still statistically significant $(p<0.0001)$ relationship was also observed for the difference between iCO and $\mathrm{CO}_{\mathrm{G} 3}$ (Fig. 2). The difference between iCO and CCO was not correlated with TSVR (Fig. 2). When only one point per patient was considered, there was no relationship between TSVR and the differences between $\mathrm{iCO}$ and $\mathrm{CO}_{\mathrm{G} 3}$ or $\mathrm{iCO}$ and $\mathrm{CCO}$, whereas a significant relationship was observed between TSVR and the difference between iCO and $\mathrm{CO}_{\mathrm{G} 2}$ (Fig. 2 in the ESM).

Separating datapoints according to the median TSVR value or even to extreme quartiles of TSVR showed that the percentage errors for $\mathrm{CO}_{\mathrm{G} 3}$ were similar for all TSVR ranges explored (Table 2 in the ESM).

Detection of changes in $\mathrm{CO}$ measurements

The AUC of the ROC curves for detecting changes in $\mathrm{iCO}$ of more than $15 \%$ in the same direction were 0.79 $(0.72-0.87)$ for $\mathrm{CO}_{\mathrm{G} 3}, 0.78(0.69-0.86)$ for $\mathrm{CO}_{\mathrm{G} 2}, 0.75$ $(0.66-0.84)$ for $\mathrm{CCO}$, and $0.51(0.42-0.62)$ for MAP (Fig. 3 in the ESM). The AUCs for $\mathrm{CO}_{\mathrm{G} 3}, \mathrm{CO}_{\mathrm{G} 2}$, and $\mathrm{CCO}$ were significantly higher than 0.5 and than MAP $(p<0.001)$ but there were no differences among the different techniques. Of note, MAP was unable to detect changes in $\mathrm{CO}$ in the same direction $(p=0.80)$. The sensitivity, specificity, positive and negative predictive values, positive and negative likelihood ratios, and percentage of correct classification (with 95\%CI) were, 
Table 2 Mean bias and limits of agreements (95\% confidence interval)

\begin{tabular}{lcc}
\hline & Bias \% $(95 \% \mathrm{CI})$ & Percentage error \% $(95 \% \mathrm{CI})$ \\
\hline All measurements (58 patients/401 measurements), without correction & \\
G3 - iCO & $-2.6\left(-4.1\right.$ to $\left.-1.2^{* \dagger}\right)$ & $29.2(25.2-34.2)$ \\
G2 - iCO & $-12.4(-14.0$ to -10.8$)$ & $32.5(26.3-36.7)$ \\
CCO - iCO & $8.2(7.0-9.5)^{*}$ & $25.4(21.3-29.5)$ \\
All measurements (58 patients/401 measurements), with correction $[23,24]$ & $30.4(23.6-37.2)$ \\
G3 - iCO & $0.2(-3.7 \text { to } 4.2)^{*}$, & $28.6(20-37.2)$ \\
G2 - iCO & $-10.3(-15.4$ to -5.3$)$ & $28.0(21.8-34.2)$ \\
CCO - iCO & $9.5(5.8-13.1)^{*}$ & $29.2(22.7-35.7)$ \\
First measurement only (58 patients/58 measurements) & $32.8(27.5-38.1)$ \\
G3 - iCO & $-2.6(-6.4 \text { to }-1.1)^{*}, \dagger$ & $25.6(19.9-31.3)$ \\
G2 - iCO & $-12.4(-16.6$ to -8.2$)$ & \\
CCO - iCO & $8.2(5.0-11.5)^{*}$ & \\
\hline
\end{tabular}

$i C O$ cardiac output measured by bolus thermodilution; $\mathrm{CO}_{\mathrm{G} 2}$ cardiac output measured by second-generation FloTrac; $\mathrm{CO}_{G 3}$ cardiac output measured by third-generation FloTrac; $C C O$ cardiac output measured by semi-continuous thermodilution

respectively, $0.78(0.60-0.89), 0.78(0.69-0.84), 0.50$ (0.36-0.65), $0.93(0.85-0.96), 3.5$ (2.4-5.1), $0.3(0.2-0.5)$, and $0.78(0.61-0.90)$ for $\mathrm{G} 3 ; 0.76(0.57-0.88), 0.75$ $(0.66-0.82), \quad 0.44 \quad(0.31-0.57), 0.92 \quad(0.85-0.96), 2.9$ (2.1-4.3), $0.3(0.2-0.6)$, and $0.75(0.63-0.84)$ for G2; and $0.72(0.55-0.85), 0.72(0.64-0.80), 0.43(0.30-0.56), 0.90$ $(0.83-0.95), \quad 2.6 \quad(1.9-3.7), \quad 0.4 \quad(0.2-0.6)$, and 0.73 (0.59-0.80) for CCO.

There were no differences in the magnitude of changes in $\mathrm{CO}$ detected by $\mathrm{iCO}$ and by the other techniques (Table 3 in the ESM).

Influence of radial versus femoral line site on the accuracy of $\mathrm{CO}$ measurements

The bias ( -3.5 vs. $-1.8 \%)$ and percentage error (30.4 vs. $26.6 \%$ ) between $\mathrm{CO}_{\mathrm{G} 3}$ and iCO were slightly greater for radial than for femoral sites, but these differences were not significant (ns). Similar trends were observed for bias $(-13.4$ and -11.6$)$ and percentage errors (33.6 vs. $30.9 \%)$ between $\mathrm{CO}_{\mathrm{G} 2}$ and $\mathrm{iCO}$ in radial and femoral sites ( $p=\mathrm{ns})$.

The difference between $\mathrm{iCO}$ and $\mathrm{CO}_{\mathrm{G} 3}$ was significantly correlated with TSVR at the radial site $\left(r^{2}=0.13\right.$, $p<0.0001)$ but not at the femoral site $\left(r^{2}=0.01\right.$, $p=0.74)$. The difference between $\mathrm{iCO}$ and $\mathrm{CO}_{\mathrm{G} 2}$ was significantly correlated with TSVR at both sites, but the correlation was greater at the radial $\left(r^{2}=0.51\right.$, $p<0.0001)$ than at the femoral $\left(r^{2}=0.19, p<0.001\right)$ site.

\section{Discussion}

Our study shows that the third-generation FloTrac software is more accurate (lower bias), as precise
$* p<0.05$ versus $\mathrm{G} 2,{ }^{\dagger} p<0.05$ versus $\mathrm{CCO}$

(\%error <30), and much less affected by SVR than the second-generation software.

Several studies have shown that the second-generation FloTrac is accurate (bias ranging between -0.30 to $+0.19 \mathrm{~L} / \mathrm{min})$ and precise $(\%$ error $<30$ ) compared with thermodilution techniques [10-13]. However, other studies showed that the second-generation FloTrac may underestimate $\mathrm{CO}$ in hyperdynamic and vasoplegic states [14-17]. In patients undergoing liver transplantation, Biais et al. [15] were the first to report a (logarithmic) relationship between FloTrac accuracy and SVR, such that the lower the SVR, the greater the bias between the FloTrac value and the reference thermodilution value. These findings were recently confirmed by Biancofiore et al. [16] in the same clinical setting. Our results obtained in septic patients are in line with these findings in that we also observed a large bias between $\mathrm{CO}_{\mathrm{G} 2}$ and $\mathrm{iCO}$ and a logarithmic relationship between TSVR and $\mathrm{CO}_{\mathrm{G} 2}$.

It has been hypothesized that significant gradients between central and peripheral arterial pulse pressures may be responsible for the underestimation of $\mathrm{CO}$ with second-generation FloTrac software in patients with low SVR. Indeed, such a gradient, likely related to a significant decrease in peripheral reflection waves, has been reported in vasoplegic and/or septic states and was shown to be reversible as soon as patients recovered [25-29]. Logically, this "decoupling" of aortic and radial pulse pressure may be responsible for an underestimation of $\mathrm{CO}$ when it is computed from a peripheral arterial pressure curve. In this regard, it is important to note that all pulse contour methods should be affected by this physiological phenomenon. Results from several studies using different pulse contour methods are consistent with this hypothesis. When comparing a pulse contour method to pulmonary thermodilution in patients with septic shock, Jellema et al. [30] showed that the limits of agreement were almost two times wider in patients with low SVR $\left(<800 \mathrm{dyn} /\left(\mathrm{s} \mathrm{cm}^{5}\right)\right)$ 

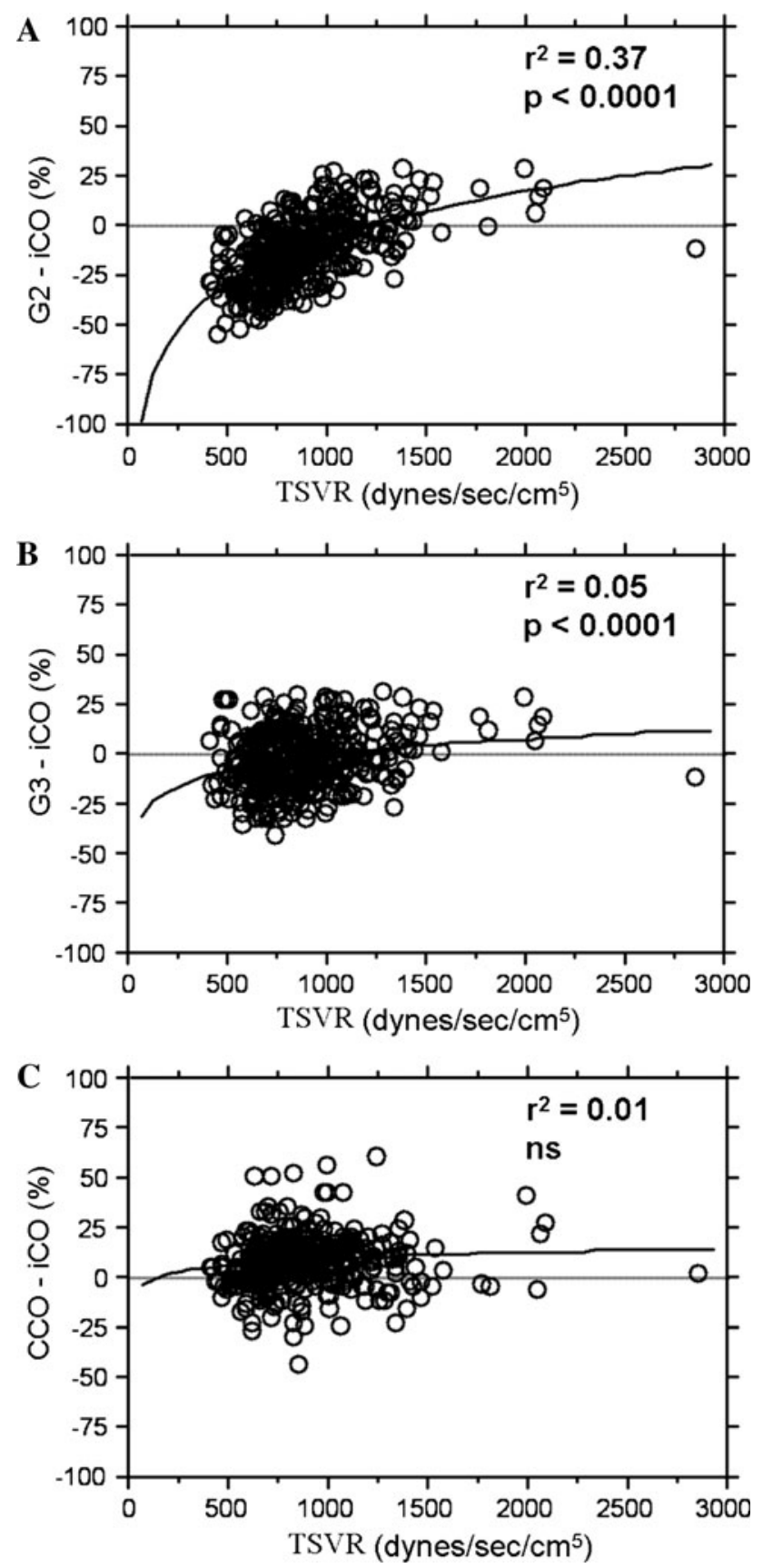

Fig. 2 Logarithmic relationships between total systemic vascular resistance (TSVR) and the differences between $\mathrm{CO}_{\mathrm{G} 2}$ and $\mathrm{iCO}$, $\mathrm{CO}_{\mathrm{G} 3}$ and $\mathrm{iCO}$, and $\mathrm{CCO}$ and iCO using all patient data Panel a shows relation between $\mathrm{CO}_{\mathrm{G} 2}$ and $\mathrm{iCO}$, panel b $\mathrm{CO}_{\mathrm{G} 3}$ and iCO, and panel $\mathbf{c} \mathrm{CCO}$ and iCO

than in other patients $\left(\mathrm{SVR}>800 \mathrm{dyn} /\left(\mathrm{s} \mathrm{cm}^{5}\right)\right)$. More recently, in cardiac surgical patients, Yamashita et al. [31] showed that when SVR was decreased dose-dependently by prostaglandin E1 infusion, the PiCCO pulse contour method underestimated $\mathrm{CO}$ by up to $40 \%$ compared with the reference thermodilution method. The same authors observed similar influences of vasodilation on bias and precision between the LiDCO pulse contour method and thermodilution [32]. Another group recently reported that differences between femoral and radial arterial traces may develop during patient course and generate differences in $\mathrm{CO}$ up to $3.0 \mathrm{~L} / \mathrm{min}$ [29]. Although we strongly suspect that a decoupling between central and peripheral pulse pressure may be responsible for the lack of accuracy of pulse contour methods in vasoplegic states, evidence to support this hypothesis is still lacking and our study was not designed to address this issue.

Consistent with this hypothesis, we nevertheless found that bias and percentage error tended to be higher in the radial than the femoral site for both $\mathrm{CO}_{\mathrm{G} 2}$ and $\mathrm{CO}_{\mathrm{G} 3}$. This was not related to factors specific to these patients, as bias and percentage errors between $\mathrm{CCO}$ and $\mathrm{iCO}$ did not differ between patients equipped with radial or femoral lines. Even though the percentage error with $\mathrm{CO}_{\mathrm{G} 3}$ using a radial line was still acceptable in these septic patients, femoral arterial lines should be preferred in these patients, whenever feasible, for $\mathrm{CO}$ monitoring and for arterial pressure measurements.

The new third-generation FloTrac software was developed from a human database containing many recordings from septic and liver transplant patients who were often vasodilated. Some proprietary arterial pressure waveform characteristics were identified in this subset of patients and integrated as new "shape variables" in the multivariate equation used to calculate and update $K$ every minute. As a result, precision has been preserved and accuracy has been improved and is now at least as good as that of semi-continuous pulmonary thermodilution (CCO), a method widely used and accepted in critically ill patients.

Our study has some limitations. First, the ideal reference method for measuring $\mathrm{CO}$ has not been described. However, the most commonly used technique is an averaged set of bolus thermodilution values taken from a pulmonary artery catheter, reported to have a precision of $10-20 \%[19,20]$. Ideally, we should have used a highly reliable reference standard to make comparisons, such as an aortic flow probe applied directly to the aorta, but this is obviously not possible in ICU patients. However, we did optimize the precision of our thermodilution measurements by using sets of measurements with a reproducibility less than 15\% [19] and using bolus thermodilution measurements as a reference. Moreover, we report similar percentage error when $\mathrm{CCO}$ was used as an alternative reference technique. Second, we studied patients with sepsis-induced vasoplegia, most of them receiving vasoactive support, with low TSVR as intended. Whether our findings may be extrapolated to patients with drug-induced (e.g., during anesthesia induction) or ischemia/reperfusion-induced (e.g., post liver reperfusion during transplantation surgery) vasoplegia remains to be determined. One may argue that changing the algorithm 
could decrease the ability of the software to measure $\mathrm{CO}$ in normal or high TSVR states. Our study was not specifically designed to test this hypothesis, but several measurements were obtained later in the patients' course when SVR had normalized. In these conditions, the bias was minimal with $\mathrm{CO}_{\mathrm{G} 3}$, as with previous versions, suggesting that the software also performs adequately in high and normal TSVR states. This should be confirmed in another prospective trial. Third, TSVR was computed without CVP, inducing an overestimation of SVR of around $15 \%$. Of note, TSVR provides a better estimate of arterial compliance, a key determinant of the relationship between stroke volume and arterial waveform, than SVR as CVP is not included in this relationship. Finally, we used both radial and femoral arterial lines. Even though these were mixed in the main analysis, a separate analysis allowed us to look at the specific behavior of each catheterization site, as reported above.

In conclusion, our study shows that in patients with sepsis, the third-generation FloTrac software is more accurate, as precise, and influenced much less by TSVR than the second-generation software. Our data also demonstrate that the overall performance of the thirdgeneration FloTrac is comparable to semi-continuous pulmonary thermodilution, a technique already widely used in septic patients.

Open Access This article is distributed under the terms of the Creative Commons Attribution Noncommercial License which permits any noncommercial use, distribution, and reproduction in any medium, provided the original author(s) and source are credited.

\section{References}

1. Erlanger J, Hooker DR (1904) An experimental study of blood pressure and of pulse-pressure in man. John Hopkins Hosp Rep 12:145-378

2. van Lieshout JJ, Wesseling KH (2001) Continuous cardiac output by pulse contour analysis? Br J Anaesth 86:467-469

3. Michard F (2007) Pulse contour analysis: fairy tale or new reality? Crit Care Med 35:1791-1792

4. Hamzaoui O, Monnet X, Richard C, Osman D, Chemla D, Teboul JL (2008) Effects of changes in vascular tone on the agreement between pulse contour and transpulmonary thermodilution cardiac output measurements within an up to 6-hour calibration-free period. Crit Care Med 36:434-440

5. Pratt B, Roteliuk L, Hatib F, Frazier J, Wallen RD (2007) Calculating arterial pressure-based cardiac output using a novel measurement and analysis method. Biomed Instrum Technol 41:403-411

6. Langewouters GJ, Wesseling KH, Goedhard WJ (1985) The pressure dependent dynamic elasticity of 35 thoracic and 16 abdominal human aortas in vitro described by a five component model. J Biomech 18:613-620

7. Langewouters GJ, Wesseling $\mathrm{KH}$, Goedhard WJ (1984) The static elastic properties of 45 human thoracic and 20 abdominal aortas in vitro and the parameters of a new model. J Biomech $17: 425-435$
8. Sander M, Spies CD, Grubitzsch H, Foer A, Muller M, von Heymann C (2006) Comparison of uncalibrated arterial waveform analysis in cardiac surgery patients with thermodilution cardiac output measurements. Crit Care 10:R164

9. Mayer J, Boldt J, Schollhorn T, Rohm KD, Mengistu AM, Suttner S (2007) Semi-invasive monitoring of cardiac output by a new device using arterial pressure waveform analysis: a comparison with intermittent pulmonary artery thermodilution in patients undergoing cardiac surgery. $\mathrm{Br}$ J Anaesth 98:176-182

10. Mehta Y, Chand RK, Sawhney R, Bhise M, Singh A, Trehan N (2008) Cardiac output monitoring: comparison of a new arterial pressure waveform analysis to the bolus thermodilution technique in patients undergoing off-pump coronary artery bypass surgery. J Cardiothorac Vasc Anesth 22:394-399

11. Prasser C, Bele S, Keyl C, Schweiger S, Trabold B, Amann M, Welnhofer J, Wiesenack C (2007) Evaluation of a new arterial pressure-based cardiac output device requiring no external calibration. BMC Anesthesiol 7:9

12. Mayer J, Boldt J, Wolf MW, Lang J, Suttner S (2008) Cardiac output derived from arterial pressure waveform analysis in patients undergoing cardiac surgery: validity of a second generation device. Anesth Analg 106:867-872, table

13. Senn A, Button D, Zollinger A, Hofer CK (2009) Assessment of cardiac output changes using a modified FloTrac/Vigileo algorithm in cardiac surgery patients. Crit Care 13:R32
14. Sakka SG, Kozieras J, Thuemer O, van Hout N (2007) Measurement of cardiac output: a comparison between transpulmonary thermodilution and uncalibrated pulse contour analysis. $\mathrm{Br}$ J Anaesth 99:337-342

15. Biais M, Nouette-Gaulain K, Cottenceau V, Vallet A, Cochard JF, Revel P, Sztark F (2008) Cardiac output measurement in patients undergoing liver transplantation: pulmonary artery catheter versus uncalibrated arterial pressure waveform analysis. Anesth Analg 106:1480-1486

16. Biancofiore G, Critchley LA, Lee A, Bindi L, Bisa M, Esposito M, Meacci L, Mozzo R, DeSimone P, Urbani L, Filipponi F (2009) Evaluation of an uncalibrated arterial pulse contour cardiac output monitoring system in cirrhotic patients undergoing liver surgery. Br J Anaesth 102:47-54

17. Della Rocca G, Costa MG, Chiarandini P, Bertossi G, Lugano M, Pompei L, Coccia C, Sainz-Barriga M, Pietropaoli P (2008) Arterial pulse cardiac output agreement with thermodilution in patients in hyperdynamic conditions. J Cardiothorac Vasc Anesth 22:681-687

18. Levy MM, Fink MP, Marshall JC, Abraham E, Angus D, Cook D, Cohen J, Opal SM, Vincent JL, Ramsay G (2003) 2001 SCCM/ESICM/ACCP/ ATS/SIS International Sepsis Definitions Conference. Crit Care Med 31:1250-1256

19. Stetz CW, Miller RG, Kelly GE, Raffin TA (1982) Reliability of the thermodilution method in the determination of cardiac output in clinical practice. Am Rev Respir Dis 126:1001-1004 
20. Critchley LA, Critchley JA (1999) A meta-analysis of studies using bias and precision statistics to compare cardiac output measurement techniques. J Clin Monit Comput 15:85-91

21. Squara P, Cecconi M, Rhodes A, Singer M, Chiche JD (2009) Tracking changes in cardiac output: methodological considerations for the validation of monitoring devices. Intensive Care Med 35:1801-1808

22. Sun JX, Reisner AT, Saeed M, Heldt T, Mark RG (2009) The cardiac output from blood pressure algorithms trial. Crit Care Med 37:72-80

23. Bland JM, Altman DG (1999) Measuring agreement in method comparison studies. Stat Methods Med Res 8:135-160

24. Myles PS, Cui J (2007) Using the Bland-Altman method to measure agreement with repeated measures. Br J Anaesth 99:309-311

25. Stern DH, Gerson JI, Allen FB, Parker FB (1985) Can we trust the direct radial artery pressure immediately following cardiopulmonary bypass? Anesthesiology 62:557-561
26. Bilo HJ, Strack van Schijndel RJ, Schreuder WO, Groeneveld AB, Thijs LG (1989) Decreased reflection coefficient as a possible cause of low blood pressure in severe septicaemia. Intensive Care Med 15:137-139

27. Hynson JM, Katz JA, Mangano DT (1998) On the accuracy of intra-arterial pressure measurement: the pressure gradient effect. Crit Care Med 26:1623-1624

28. Dorman T, Breslow MJ, Lipsett PA, Rosenberg JM, Balser JR, Almog Y, Rosenfeld BA (1998) Radial artery pressure monitoring underestimates central arterial pressure during vasopressor therapy in critically ill surgical patients. Crit Care Med 26:1646-1649

29. Smith J, Camporota L, Beale R (2009) Monitoring arterial blood pressure and cardiac output using central or peripheral arterial pressure waveforms. In: Vincent JL (ed) 2009 Yearbook of intensive care and emergency medicine. Springer, Heidelberg, pp 285-296
30. Jellema WT, Wesseling KH, Groeneveld AB, Stoutenbeek CP, Thijs LG, van Lieshout JJ (1999) Continuous cardiac output in septic shock by simulating a model of the aortic input impedance: a comparison with bolus injection thermodilution.

Anesthesiology 90:1317-1328

31. Yamashita K, Nishiyama T, Yokoyama T, Abe H, Manabe M (2008) The effects of vasodilation on cardiac output measured by PiCCO. J Cardiothorac Vasc Anesth 22:688-692

32. Yamashita K, Nishiyama T, Yokoyama T, Abe H, Manabe M (2007) Effects of vasodilation on cardiac output measured by PulseCO. J Clin Monit Comput 21:335-339 